\title{
correspondence
}

\section{MLS international standard}

SIR,--It is with regret that I report an error in the article 'Astronomy's own cloud' (9 June, page 478). The Australian system, 'Interscan', one of several Microwave Landing System (MLS) proposals, has not been adopted as the next international standard, and has not (yet) beaten all comers. The matter is, sadly, complicated if not bedevilled by partisan politics and if you were to read certain American reports, for example Microwave Systems News (June 1977, page 33) you would learn: "US Landing System going world wide".

The pedantic, boring truth is that the All Weather Operations Panel of the International Civil Aviation Organisation (ICAO) met in Montreal last March to consider the various MLS proposals. They recommended by a narrow majority vote (6-4), that the 'scanning-beam' (US-Australian) MLS scheme be submitted to the ICAO Air Navigation Commission for consideration for adoption as the international standard at an ICAO meeting to be called later this or early next year. Recommendation for adoption-no more, no less.

It is not altogether clear from the generally accessible published material just what the differences between the American system and the Australian 'Interscan' are. We can certainly say that the Australian idea was taken over by the Americans, whose own originally proposed schemes were demonstrated to be less than competitive. In this sense the Australians do indeed have cause for pride.

One must not forget that the Germans and the English both have advanced MLS proposals, and that the selection at Montreal of the USAustralian scheme was perhaps helped more by procedural niceties than by an honourable and convincing demonstration of the inferiority of the European work (Aviation Week and Space Technology, 28 March, page 26 et seq., Frankfurter Allgemeine Zeitung, 14 April, page 8 ). This was the subject of objections at the time and the reason for protest abstentions in various votes during the meeting.

One cannot altogether blame the Australians for blowing their own trumpet since they have suffered sorely in publicity at the expense of the Americans-their trumpet should nevertheless play the written notes and not extemporise.

It is to be expected that the European interests in MLS will pursue vigorously a re-appraisal of the Montreal deliberations, with a view to demonstrating the technical superiority of one of the systems over the others -a demonstration which has not yet been attempted.

$$
\begin{gathered}
\text { Yours faithfully, } \\
\text { DAvid LL. HiLls } \\
\text { Max-Planck-Institut für } \\
\text { Radioastronomie, Bonn }
\end{gathered}
$$

\section{Wind power for the UK}

Sir,--Dr Clement states that my estimates of wind-power are "grossly exaggerated" and that the environmental impact would be unacceptable. He compares my results with those of the recent Department of Energy report The prospects for the generation of electricity from wind-energy in the United Kingdom which considers the installation of windmills on hill-top sites (many of which would undoubtedly be environmentally unacceptable besides involving greater construction and transmission costs) and within a $15 \mathrm{~km}$ coastal belt. The total area involved in deriving their "upper limit on energy" is confined to about $1 \%$ of the UK land area. The more dispersed system which I discussed covers-as Dr Clement correctly computes-some $5 \times 10^{4} \mathrm{~km}^{2}$ of land area, reduces the transmission costs per $\mathrm{kW}$, and provides 20 itimes the energy.

The impact of wind generators on other land uses such as agriculture is minimal, and the visual impact must be judged in relation to that associated with any other scheme capable of providing comparable useful energy. If, for example, it were proposed to provide the UK energy gap predicted by the end of the century by the construction of new nuclear capacity on coastal sites, much of the south and east coasts of the country would require an average density of nuclear stations corresponding to about $0.2 \mathrm{GW} \mathrm{km}^{-1}$ of coastline. If, as in my wind example, environmental and other objections permit only about one-third of the coastline to be so used, these areas will require about one $275 \mathrm{kV}$ twin-wire transmission line running inland for every $2 \mathrm{~km}$ of coastline. At 4 towers per $\mathrm{km}$ the density of pylons (whose construction is very similar to that of the windmills 1 considered) is then about twice that of the windmills. The nuclear stations themselves would of course involve both visual and other environmental problems as well.

Dr Clement seems to prefer to ignore the energy problems which we, and other countries, now facc; perhaps he believes-as the Secretary of State has recently stated-that $13 \mathrm{GW}$ of additional nuclear capacity (half in FBRS) would be more than adequate to meet our energy needs "in the foreseeable future" (Guardian, 3 June). Although this capacity would replace the oil-fired generating stations now in use (11 GW), it could make little contribution to the much larger energy demand at present provided by oil and gas for transport, industry and the heating of buildings. Owing to the large fluctuations in the latter, an installed capacity of 200-250 GW would be needed by the end of the century.

A nuclear capacity of $13 \mathrm{GW}$ may indeed represent what it is feasible to build on this time scale, and if so it is clearly essential both to introduce every possible economy measure now and to proceed as fast as possible with the development and installation of alternative sources capable of making a more significant contribution. Wind-power is the most highly developed, has a large potential and is the cheapest, although wave, new forms of tidal and direct solar energy may also be important.

In comparing the cost of wind energy with that derived from nuclear and fossil fuel stations the Department of Energy report has considered only the replacement of base-load electricity, rather than the much more important energy gap discussed above. Owing to the large fluctuations in this energy demand, it is not permissible, as the report has done, to include the interest on capital for wind generators but exclude it for conventional systems, and the high costs they derive for windpower are not relevant; the actual costs, both capital and running, for producing a given useful energy from wind are about onc-third those of a nuclear system.

$$
\begin{aligned}
& \text { Yours faithfully, } \\
& \text { MARTIN RYLE }
\end{aligned}
$$

Cavendish Laboratory,

Madingley Road,

Cambridge, UK 